\title{
Is there a right time for surgery in paraplegic patients secondary to non traumatic spinal cord compression?
}

\author{
Há um período exato para cirurgia em pacientes com paraplegia secundária \\ à compressão medular não traumática?
}

Leonardo Giacomini ${ }^{1}$, Roger Neves Mathias ${ }^{1}$, Andrei Fernandes Joaquim ${ }^{1}$, Mateus Dal Fabbro ${ }^{1}$, Enrico Ghizoni ${ }^{1}$, Helder Tedeschi ${ }^{1}$

\begin{abstract}
Paraplegia is a well-defined state of complete motor deficit in lower limbs, regardless of sensory involvement. The cause of paraplegia usually guides treatment, however, some controversies remain about the time and benefits for spinal cord decompression in nontraumatic paraplegic patients, especially after 48 hours of the onset of paraplegia. The objective of this study was to evaluate the benefits of spinal cord decompression in such patients. We describe three patients with paraplegia secondary to non-traumatic spinal cord compression without sensory deficits, and who were surgically treated after more than 48 hours of the onset of symptoms. All patients, even those with paraplegia during more than 48 hours, had benefits from spinal cord decompression like recovery of gait ability. The duration of paraplegia, which influences prognosis, is not a contra-indication for surgery. The preservation of sensitivity in this group of patients should be considered as a positive prognostic factor when surgery is taken into account.
\end{abstract}

Keywords: Decompression; Paraplegia; Spinal injuries/complications

\section{RESUMO}

A paraplegia é uma condição de déficit motor completo dos membros inferiores, independente do envolvimento de sensibilidade. A causa da paraplegia normalmente guia 0 tratamento, porém existem controversas sobre 0 momento e 0 benefício da descompressão medular em pacientes paraplégicos, principalmente após 48 horas do início dessa condição. 0 objetivo deste trabalho foi avaliar o beneficio da descompressão medular nesses pacientes. Foram descritos três pacientes com paraplegia secundária à compressão medular não traumática, sem déficits sensoriais e que foram submetidos à cirurgia após 48 horas do início dessa condição. Todos os pacientes, inclusive aqueles com mais de 48 horas do início dos sintomas, apresentaram melhora neurológica com a descompressão medular, como a recuperação da habilidade de marcha. A duração da paraplegia, que influencia no prognóstico, não é uma contraindicação absoluta para o procedimento cirúrgico. A preservação de sensibilidade desse grupo de pacientes deve ser considerada como fator prognóstico positivo quando a cirurgia for levada em conta.

Descritores: Descompressão; Paraplegia; Traumatismos da coluna vertebral/complicações

\section{INTRODUCTION}

Paraplegia is a well-defined state of complete motor deficit in lower limbs, regardless of sensory involvement, with muscular strength grading zero. It may be secondary to neoplastic, vascular, degenerative, inflammatory or traumatic disease ${ }^{(1,2)}$.

The cause of paraplegia guides the treatment. However, some controversies remain about the timing for spinal cord decompression in patients with muscular strength grading zero, especially when the sensory modality is damaged ${ }^{(1)}$.

This report discusses an atypical evolution of three patients submitted to spinal cord decompression after more than 48 hours of onset of paraplegia.

All the patients had the muscular strength of their four limbs evaluated. The preservation of pain and tactile sensitivity were also assessed. All patients included in this report had complete paraplegia with

${ }^{1}$ Universidade Estadual de Campinas - UNICAMP, São Paulo (SP), Brazil.

Corresponding author: Leonardo Giacomini - Rua Roxo Moreira, 200 - Cidade Universitária - Zip code: 13083-590 - Campinas (SP), Brazil - Phone: (55 19) 9797-6041 - E-mail: leogiacomini@yahoo.com.br Received on: May 25, 2012 - Accepted on: Sep 5, 2012 
partial preservation of tactile and pain sensitivity, below the neurological level.

\section{CASE REPORT}

\section{Case 1}

A 33-year-old man, complaining of dorsal thoracic pain for 2 months, was admitted to the emergency unit with paraplegia for 4 days and urinary retention with partially preserved tactile and painful sensitivity in lower limbs. On clinical examination, a skin lesion in his right hand was detected and suggested cutaneous melanoma. A magnetic resonance (MR) of the thoracic spinal segment was compatible with an extradural lesion located in the dorsal portion of the cord at T8 level (Figure 1). He underwent a laminectomy $\mathrm{T} 6$ to $\mathrm{T} 9$ on the fourth day after the total paraplegia had begun. He was treated with radiotherapy 21 days after the surgical procedure. During a 6-month follow-up the patient regained full sphincter control, lower limbs' strength (grade IV), and walked without assistance.
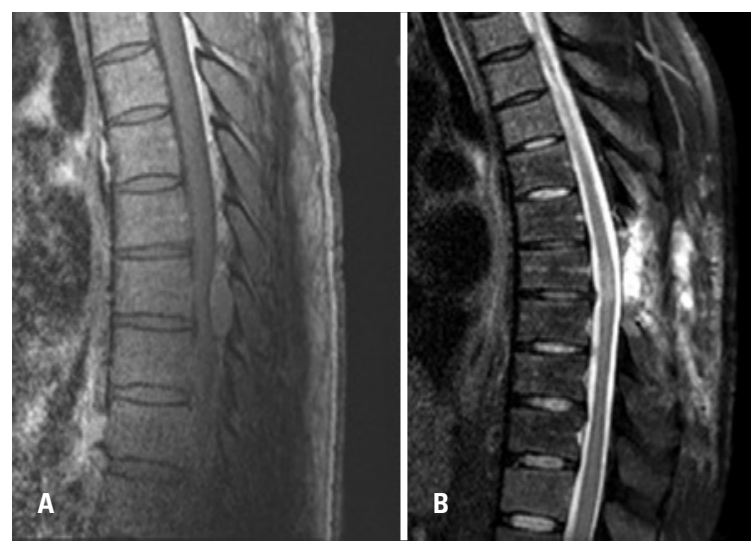

Figure 1. Sagittal T1 sequence magnetic resonance showing a posterior thoracic spinal cord compression at the thoracic segment before (A) and after (B) (T2 sequence) complete resection

\section{Case 2}

A 37-year-old woman, was admitted to the emergency unit with progressive paraparesis, muscular strength grade $\mathrm{I}$ in the right lower limb (RLL) and grade II in the left lower limb (LLL) due to a right-lateral T10-T11 disc herniation as revelead by MR of the thoracic spine (Figure 2). A right transpedicular microdissectomy in T11 with medial right T11 pedicle resection was performed concurrently to a pedicle screw fixation (Figure 2).
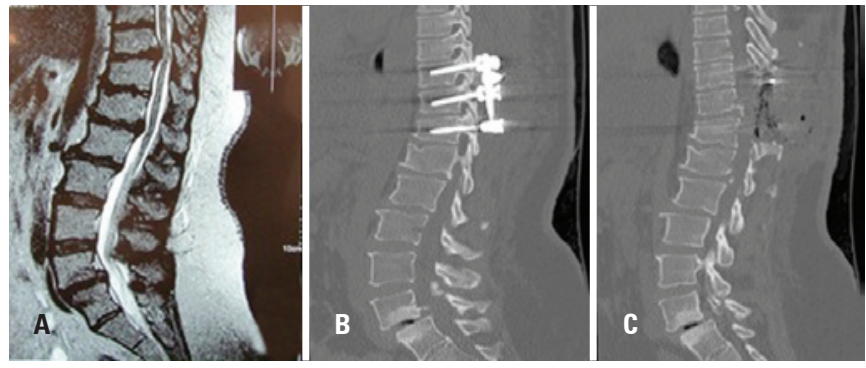

Figure 2. Sagittal lumbar T2 sequence magnetic resonance showing a T11-12 disc herniation with spinal cord compression (A); CT scan showing sagittal reconstruction after microdissectomy/transpedicular decompression and T10-T12 laminectomy with pedicle screw fixation (B and C)

After a 1-month follow-up, the patient presented muscular strength grade III in the RLL and grade IV in the LLL, and could walk with support. However, two months after the surgery the patient presented a sudden paraplegia and lost sphincter control. However, her pain and tactile sensitivity in both legs were maintained. She underwent an emergency T10-11-12 laminectomy (Figure 2) after five days of the onset of paraplegia. Ligament and facet hypertrophy and intense compression of the medullary canal were intraoperative findings. Eight months after the second procedure she was able to walk with assistance, had sphincter control and bilateral muscular strength grading IV.

\section{Case 3}

A 54-year-old, man was admitted to our service. He had multiple comorbidities (diabetes, systemic hypertension, heart failure, previous pulmonary thromboembolism and coumarin use) paraplegia, urinary retention and erectile dysfunction lasting for 1 year but with preserved tactile and painful sensitivity in lower limbs. Thoracic spine MR was compatible with T1-T2 meningioma (Figure $3)$. The patient underwent total tumor resection, with a three-level laminectomy (Figure 3). After 9 months, he

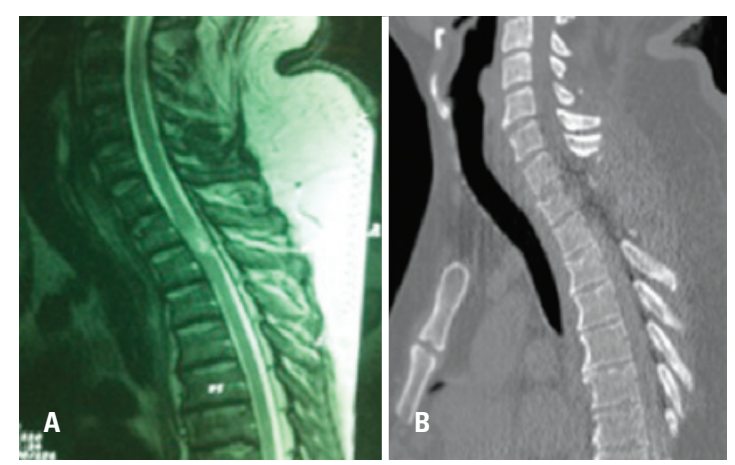

Figure 3. Sagittal T2 sequence thoracic magnetic resonance showing lesion compression of spinal cord at T1-T2 (intradural meningioma), and CT scan showing the complete resection (B) 
presented bilateral muscular strength grading IV with mild spasticity, and was able to walk with support. In addition, he discontinued the use of urinary catheter and regained sexual activity.

\section{DISCUSSION}

In traumatic paraplegia, spinal cord decompression is not often recommended since neurological recovery is unusual and may lead to cerebrospinal fluid (CSF) leakage ${ }^{(1)}$.

The American Spine Injury Association (ASIA) ${ }^{(2)}$ classifies traumatic paraplegia into two groups: first, those with complete injuries (also known as ASIA A), without motor and sensory function, and below the neurological level; second, those with preserved sensory function despite the lack of any motor function (paraplegic) also known as ASIA B. Both groups have distinct neurological recovery prognosis as stated by Harrop et al. who evaluated the neurological outcome of 282 patients who suffered thoracic and lumbar spine trauma. These authors observed that only $7.7 \%$ of patients, initially classified as ASIA A, showed some degree of neurological improvement compared with $66.7 \%$ of neurological improvements seen in patients classified as ASIA B after 1-year follow-up. Such data suggest that sensitivity preservation, despite total muscular strength loss, is an important prognostic factor in patients with spinal trauma ${ }^{(3)}$.

However, the neurological outcome of non-traumatic paraplegia secondary to cord compression is uncertain and not well established like in traumatic spinal cord injury (SCI). Regarding neoplastic disease some case series and literature reviews suggest that surgical decompression should benefit those patients with less than 24 or 48 hours of onset of paraplegia ${ }^{(4)}$. There is some agreement that the neurological outcome after surgery or radiotherapy is directly related with the neurological status before the treatment ${ }^{(5)}$.

Considering these data, some authors suggest that surgical treatment should not to be indicated if the paraplegia was established for more than 24 to 48 hours, disregarding sensitivity preservation as a potential variable for surgical indication ${ }^{(4)}$. Unlike patients with traumatic SCI, sensory preservation, even partial, is not mentioned as a prognostic factor to consider when deciding for surgical decompression.

We emphasize that our literature review did not distinguish patients with total paralysis and sensory preservation (at least one sensorial modality preserved) from those with paraplegia and full sensitive deficit ${ }^{(6)}$. Similarly to patients with traumatic SCI ASIA B, we believe that sensitive preservation in any degree (partial or total) is a prognostic factor that should be considered when deciding on the type of treatment. Such information agrees with the three cases reported in this paper.

Some studies reporting reversal paraplegia were founded in the literature review done for this report. In the laminectomy era, Buckman and Bloomer reported neurological improvement in $7 \%$ of patients with paraplegia secondary to spinal metastatic disease and submitted to surgical decompression compared with $35 \%$ of patients with partial motor deficit who showed neurological improvement ${ }^{(7)}$. This author's study, in the era of non-instrumental spinal surgery, proposed that the preoperative neurological status is an important outcome factor, as described previously, nevertheless, neurological improvement can be obtained even in patients with total paraplegia ${ }^{(8)}$. However, these authors did not mention those cases with complete motor deficit from those with preserved sensibility.

DeWald et al. reported clinical improvement in 5 patients with paraplegia from 11 submitted to surgical decompression for spinal metastatic disease. Although they reported a reasonable outcome, they concluded that surgical decompression should be carefully evaluated in paraplegic patients, once the morbidity it is not negligible ${ }^{(8)}$.

In the modern era of spinal surgery, Brohi et al. reported a patient that was sumitted to a thoracic epidermoid tumor resection after 12 years of paraplegia ${ }^{(9)}$ with full recovery. Two studies also report paraplegia recovery after treatment of spinal dural arteriovenous fistula (endovascular embolization followed by surgery) ${ }^{(10)}$. These cases state the idea that paraplegia is not an irreversible condition in some specific situations.

Apart from neoplastic disease, surgical decompression of paraplegic patients associated with degenerative is under-reported given the painless behavior of this type of disease (case 2). Both paraplegic patients described here with neoplasm involvement of the spinal cord (metastatic melanoma and meningioma, cases 1 and $3)$ regained motor function although the surgery was performed later (4 days and 1 year after the clinical onset). A muscular strength grading IV was seen in the follow-up in both patients.

\section{CONCLUSION}

In some cases of non-traumatic spinal cord compression paraplegia is not an irreversible condition. The duration of paraplegia, which influences prognosis, is not an 
absolute contra-indication for surgery. Moreover, tactile and pain sensitivity preservation is considered a positive factor for surgery. A complete evaluation of all the sensitivity modalities is mandatory in these groups of patients. Further studies should be conducted to clarify these issues.

\section{REFERENCES}

1. Bohlman HH, Freehafer A, Dejak J. The results of treatment of acute injures of the upper thoracic spine with paralysis. J Bone Joint Surg Am. 1985;67(3):360-9.

2. Marino RJ, Barros T, Biering-Sorensen F, Burns SP, Donovan WH, Graves DE, Haak M, Hudson LM, Priebe MM; ASIA Neurological Standards Committee 2002. International standards for neurological classification of spinal cord injury. J Spinal Cord Med. 2003;26 Suppl 1:S50-6.

3. Harrop JS, Naroji S, Maltenfort MG, Ratliff J, Tjoumakaris SI, Frank B, et al. Neurologic improvement after thoracic, thoracolumbar, and lumbar spinal cord(conus medullaris) injuries. Spine (Phila Pa 1976). 2011;36(1):21-5.
4. Klimo P Jr, Kestle JR, Schmidt MH. Treatment of metastatic spinal epidural disease: a review of the literature. Neurosurg Focus. 2003;15(5):E1.

5. Levack P, Graham J, Collie D, Grant R, Kidd J, Kunkler I, Gibson A, Hurman D, McMillan N, Rampling R, Slider L, Statham P, Summers D; Scottish Cord Compression Study Group. Don't wait for a sensory level--listen to the symptoms: a prospective audit of the delays in diagnosis of malignant cord compression. Clin Oncol (R Coll Radiol). 2002;14(6):472-80.

6. Schoeggl A, Reddy M, Matula C. Neurological outcome following laminectomy in spinal metastases. Spinal Cord. 2002;40(7):363-6.

7. Bruckman JE, Bloomer WD. Management of spinal cord compression. Semin Oncol.1978;5(2):135-40.

8. DeWald RL, Bridwell KH, Prodromas C, Rodts MF. Reconstructive spinal surgery as palliation for metastatic malignancies of the spine. Spine (Phila Pa 1976). 1985;10(1):21-6.

9. Brohi SR, Qureshi SM, Rajput SS, Bhatti NK. Thoracic intramedullary epidermoid with paraplegia for 12 years. J Coll Physicians Surg Pak.

10. Prieto R, Pascual JM, Gutiérrez R, Santos E: Recovery from paraplegia after the treatment of spinal dural arteriovenous fistula: case report and review of the literature. Acta Neurochir (Wien). 2009;151(11):1385-97. 